\title{
INFORMACIÓN
}

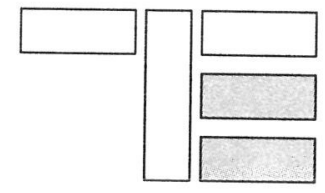





\section{SEMINARIO INTERUNIVERSITARIO DE TEORÍA DE LA EDUCACIÓN}

La globalización es uno de los acontecimientos que están marcando la Historia contemporánea. La política, la economía, la cultura, la tecnología... se encuentran en este fenómeno de internacionalización. La globalización es tan política como cultural y financiera. La sociedad-red diluye las limitaciones espacio-temporales, posibilita nuevas formas para el encuentro entre grupos humanos; los avances tecnológicos facilitan que los mercados traspasen las fronteras y se mundialicen, la dependencia económica entre los países crece; la tecnología ha hecho del planeta una pequeña aldea definida por la comunicación y la interdependencia. En suma, esta nueva cultura global ha calado en los países occidentales, difundiéndose gracias a los medios de comunicación.

Junto a los fenómenos descritos, se ha producido también una movilidad de personas, posiblemente sin parangón, en ocasiones propiciada por la caída de las fronteras. Otras veces, si no en busca de paraísos, sí en busca de una tierra menos hostil o más grata, donde la vida sea más llevadera. Este contexto resulta en buena medida positivo, pero también, en gran parte, generador de nuevas problemáticas: lo que es fuente de progreso y bienestar es, al mismo tiempo, causa de desigualdades, desencuentro, deshumanización. La educación, así como la reflexión y contribución científica sobre la misma, han de aportar sus respuestas.

Las líneas anteriores justifican sobradamente la elección de esta nueva realidad como temática para el XXI Seminario Interuniversitario de Teoría de la Educación, que, bajo el título "Globalización, inmigración y educación" se celebró en Granada - Granada la Bella, como la llamó Ganivet- entre los días 18 y 20 de noviembre de 2002. Cuatro ponencias fueron marco para treinta y una addenda, trabajos en torno a los que se reunieron veintidós universidades y más de medio centenar de participantes en este foro de reflexión e intercambio científico.

La primera ponencia, coordinada por el profesor Joaquín García Carrasco, nos recuerda que el progreso tecnológico ha supuesto cambios sustanciales en el contexto social, en las condiciones de vida, en las interrelaciones y el comportamiento de las personas: los grupos humanos han recibido el impacto profundo de las NTIC. Desde el punto de vista pedagógico, interesan las repercusiones que este cambio de paradigma tiene sobre el aprendizaje (cognitivo y afectivo) en los contextos formales e informales del universo educativo: sus riesgos, sus ventajas, sus exigencias y posibilidades. 
Ante la multiculturalidad como hecho vinculado con la inmigración, la segunda ponencia, que coordinó el profesor José Antonio Jordán, plantea la necesidad de convivir. Ésta es la finalidad a la que se da respuesta desde el planteamiento pedagógico que busca formar actitudes y conductas interculturales sólidas. Interculturalidad y convivencia pasan por una escuela abierta al entorno, superadora de actitudes xenófobas y racistas, centrada en la ética de la alteridad y presidida por el principio de igualdad: igualdad de derechos y deberes desde la que integrarse de forma normalizada en una vida colectiva regida por la reciprocidad.

Partiendo del análisis cuantitativo de la inmigración en la Comunidad Europea y en España - más pormenorizada en aquellas comunidades autónomas donde la afluencia de inmigrantes es mayor-, coordinada por el profesor Julio Vera, la tercera ponencia aporta reflexiones, experiencias y propuestas sobre la escolarización de los hijos de inmigrantes y las políticas sociales y educativas de atención a la inmigración. Las experiencias concretas de programas educativos y sociales vienen marcadas por la búsqueda de adaptación mutua, integración, colaboración, capacitación del profesorado, etc., que, en medio de la multiculturalidad, garanticen identidades culturales sólidas sobre las que fundamentar la convivencia pacífica y la unidad en un mundo diverso y plural.

Bajo la coordinación del profesor Enric Roca, la cuarta ponencia aborda la realidad de la inmigración en contextos de educación formal y no formal aportando programas y acciones aducativas reales, que, si bien se consideran por los autores de la ponencia únicamente aún un punto de referencia más que conclusiones definitivas, tienen el valor sugeridor de la experiencia en espacios educativos concretos que pueden ser punto de referencia para acciones en otros lugares.

Balance positivo el de este seminario tras el que recoge el testigo la Universidad de Barcelona, ciudad donde bajo el lema Otros lenguajes en educación, tendrá lugar el próximo SITE en noviembre de 2003.

Pilar Casares García

Universidad de Granada 